\title{
A Ten-Year Review of the Pattern and Outcome of Childhood Diabetes in Two State Teaching Hospitals in South-West Nigeria
}

This article was published in the following Dove Press journal: Diabetes, Metabolic Syndrome and Obesity: Targets and Therapy

\author{
Isaac Oludare Oluwayemi $\mathbb{D I}^{\prime}$ \\ Olusola Adetunji Oyedeji $\mathbb{D}^{2}$ \\ Emmanuel Oluwatosin Adeniji \\ Adebukola Bidemi Ajite (ID) \\ Adefunke Olarinre Babatola (iD ${ }^{\prime}$ \\ Adewuyi Temidayo Adeniyi (iD ${ }^{1,2}$ \\ Ezra Olatunde Ogundare (D) ' \\ Oladele Simeon Olatunya (iD) \\ Temitope Opeyemi Ayeni ${ }^{3}$ \\ Ayotunde Emmanuel Ajibola (iD) ${ }^{4}$ \\ 'Department of Paediatrics, Faculty of \\ Clinical Sciences, College of Medicine, \\ Ekiti State University, Ado-Ekiti, Ekiti \\ State, Nigeria; ${ }^{2}$ Department of \\ Paediatrics, Faculty of Clinical Sciences, \\ College of Health Science, LAUTECH, \\ Osogbo, Osun State, Nigeria; \\ ${ }^{3}$ Department of Paediatrics, LAUTECH \\ Teaching Hospital, Osogbo, Osun State, \\ Nigeria; ${ }^{4}$ Department of Paediatrics, Ekiti \\ State University Teaching Hospital, Ado- \\ Ekiti, Ekiti State, Nigeria
}

Background: Childhood diabetes mellitus is a poorly researched topic in Nigeria. Its contribution to morbidity and mortality is vague. This study intends to provide additional information to the background data in Nigeria and hopefully proffers strategies to improving the outcome of this disease.

Methods: This is a retrospective descriptive study of all children managed for childhood diabetes mellitus at the Ekiti State University Teaching Hospital (EKSUTH) and LAUTECH Teaching Hospital (LTH), South West Nigeria, over a 10 year period. Relevant information was obtained from the case notes of all affected children. Data obtained were analysed with SPSS version 20 software.

Results: A total of 20 children were treated for diabetes mellitus (DM); there were 7 $(35.0 \%)$ boys and $13(65.0 \%)$ girls giving a M:F ratio of 1.0:1.9. Age range at presentation was 5 to 16 years and the mean age at presentation was $12.7 \pm 2.89$ years. Diabetic ketoacidosis (DKA) was the most common form of presentation in 13 (65.0\%). Most [18 $(90.0 \%)]$ of the patients had type $1 \mathrm{DM}$. Type $2 \mathrm{DM}$ and glucocorticoid-induced diabetes mellitus were recorded in a case each, Eighteen (90\%)patients had not been previously diagnosed by any form of screening prior to their presentation and admission in the hospital. Seven $(35.0 \%)$ of the patient's care were affected by parental financial constraints. Five mortalities were recorded and one left against medical advice while the majority [14 (70.4\%)] were discharged well and alive. The association between the greater numbers of deaths recorded in children with financial constraints was statistically significant $(p<0.05)$. Conclusion: Type $1 \mathrm{DM}$ remains the most predominant form of diabetes in children and most of the patients presented in DKA. The proportion of deaths in this study is unacceptably high. There is a need to proffer strategies for earlier detection and management of children with diabetes mellitus prior to the onset or development of DKA and there is a need to assist with the funding of the care of children with diabetes mellitus.

Keywords: pattern, outcome, childhood diabetes, Nigeria
Correspondence: Isaac Oludare Oluwayemi

Department of Paediatrics, Faculty of

Clinical Sciences, College of Medicine,

Ekiti State University, Ado-Ekiti, Ekiti

State, Nigeria

Tel +2348034052536

Email isaac.oluwayemi@eksu.edu.ng

\section{Introduction}

Globally more than 1.1 million children and adolescents below 20 years have type 1 diabetes mellitus. ${ }^{1}$ However, the prevalence of diabetes mellitus in Nigerian children is still unknown and Nigerian-based studies on this topic are scarce. ${ }^{1-3}$ It is well documented that the most common cause of death in childhood diabetes world-wide is lack of access to insulin and this is worse in poverty-stricken developing countries where health care financing is mostly out-of-pocket. ${ }^{4}$ Diabetic ketoacidosis (DKA) is the most common presentation of childhood 
diabetes mellitus as documented by most of the previous studies. ${ }^{4-8}$ DKA, a medical emergency, often results from late presentation, diagnosis, and management of childhood diabetes mellitus.

Over the years, IDF/Life for a Child (www.lifefora child.org) in collaboration with the International Society for Pediatrics and Adolescent Diabetes (ISPAD) and other organizations has been sponsoring provision of free insulin for diabetic children in developing countries in a bid to greatly reduce the morbidity and mortality of childhood diabetes. ${ }^{5}$ All these efforts from international societies are few drops in the ocean because of the prevalent poverty in most developing countries where the most common initial presentation of childhood diabetes is diabetic ketoacidosis $(\mathrm{DKA})^{6-10}$ with a mortality of $24-28 \%$ from cerebral edema. ${ }^{11}$

Intensive training of indigenous paediatric endocrinologists began a decade ago in Nigeria by the Paediatric and Endocrinology Training Centre for West Africa (PETCWA) in collaboration with ISPAD and the European Society for Paediatric Endocrinologist (ESPE) and this has been of great help in offering specialized care to diabetic children in Nigeria and West Africa, through the products of this training.

We aim to highlight the pattern of diabetes presentation and its outcome in two of the state tertiary hospitals in Western Nigeria, over this ten year period. We hope that the findings from this study will help in proffering strategies to improve the outcome of diabetes and possibly detect diabetes earlier.

\section{Method}

The index study is a retrospective descriptive study of all children managed for childhood diabetes at the Ekiti State University Teaching Hospital (EKSUTH) and LAUTECH Teaching Hospital (LTH) for a 10 year period from March 2010 to March 2020. The corresponding author established and coordinated the paediatric endocrine clinics at both EKSUTH and LTH. Ethical clearance for the study was obtained from the Ethics and Research Committee of the Ekiti State University Teaching Hospital, Ado-Ekiti and LAUTECH Teaching Hospital, Osogbo, Osun State.

Bio-data and essential clinical information about patients seen at the endocrinology clinics of both centres were entered into an Excel spreadsheet at presentation for effective follow up of patients and for updated recording to receive support like free insulin from IDF/Life for a Child when available. Relevant data such as age, sex, mode of presentation and outcome were extracted from the case notes. Patients' ages were categorized into two groups (5-10 years and above 10 years). The frequency of different types of diabetes found in the patients seen during the study period was determined. Outcome was categorized as alive, dead and left against medical advice (LAMA). Survival and wellbeing of the patients were also followed for two years following diagnosis of diabetes and included in the categorization of the outcome as dead or alive if the patients died of a diabetes related illness or were alive, respectively, within two years of diagnosis.

Diagnosis of diabetes mellitus was based on the following criteria at both teaching hospitals and their diabetic conditions were treated according to hospital protocols which are the same in both units. Diabetes mellitus is diagnosed in a child if the random blood glucose is greater than or equal to $11.1 \mathrm{mmol} / \mathrm{L}$ and confirmed if fasting blood glucose is greater than or equal to $7 \mathrm{mmol} / \mathrm{L}$ with the attendant symptoms of glycosuria, polyuria, polydipsia, and weight loss. ${ }^{12}$

Data obtained were entered into a personal computer, analysed using the software, Statistical Package for Social Sciences (SPSS) for Windows, version 20 (SPSS version 20). Categorical variables were expressed in proportions, ratios and percentages. Categorical variables were compared using the Chi-square $\left(\chi^{2}\right)$ test. Statistical significance was set at "p" value less than 0.05 .

\section{Results}

A total of 20 children were treated for diabetes mellitus in two state teaching Hospitals (Ekiti State University Teaching Hospital, Ado-Ekiti and LAUTECH Teaching Hospital, Osogbo), between March 2010 to March 2020. Fourteen $(70.0 \%)$ were treated at EKSUTH while $6(30.0 \%)$ were seen at LTH. The 14 diabetic patients treated at EKSUTH accounted for $9.3 \%$ of the 151 patients with paediatric endocrine disorders seen at EKSUTH Paediatric Endocrine Clinic while the six diabetic children treated at LTH represented $16.2 \%$ of the 37 patients with paediatric endocrine disorders seen at LTH during the study period.

\section{Age and Sex Distribution of Children Studied}

The age range at presentation was from 5 to 16 years. The mean age at presentation was $12.7 \pm 2.89$ years. The majority $16(80.0 \%)$ of the diabetic patients at presentation were in the age group above 10 years. 


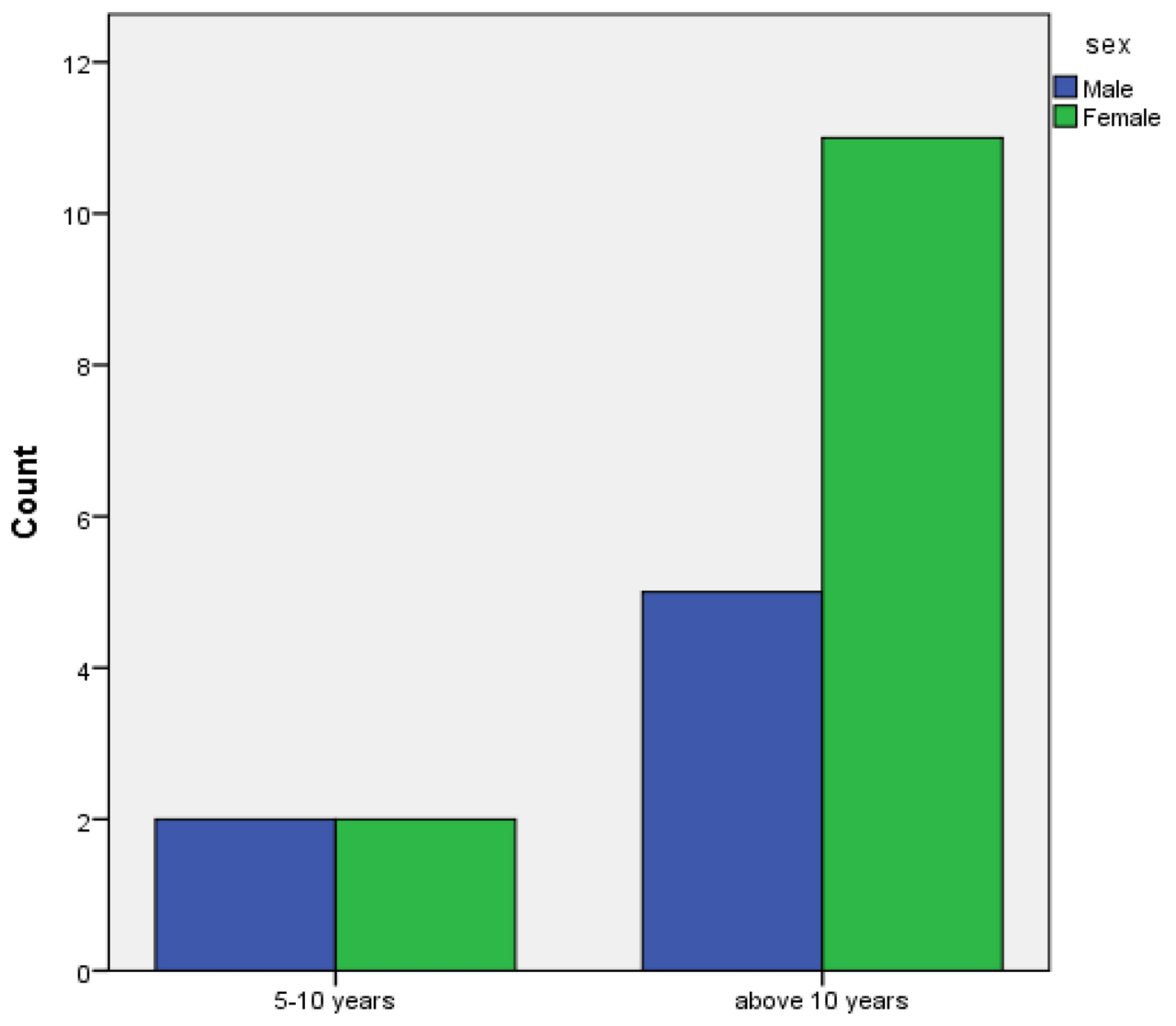

Age Distribution

Figure I Sex and age distribution of diabetic patients.

Overall, there were $7(35.0 \%)$ boys and $13(65.0 \%)$ girls giving a $\mathrm{M}: \mathrm{F}$ ratio of 1:1.9. However, there was equal gender prevalence in the age group 5-10 years while there was predominant female preponderance in the age group above 10 years of age (Figure 1).

\section{Presentation and Classification of}

\section{Diabetes Mellitus Among Studied Patients}

Diabetic ketoacidosis was the predominant mode of presentation in $13(65.0 \%)$ of the 20 children. Five $(83.3 \%)$ of the patients at LTH and $8(57.1 \%)$ at EKSUTH presented in DKA; the other forms of presentation are highlighted in Table 1. Most, 18 (90.0\%), of the patients had type $1 \mathrm{DM}$, while type 2 diabetes mellitus and glucocorticoid-induced diabetes mellitus were recorded in $1(5 \%)$ child each (Table 2). Two (10\%) of the patients (one from each centre) had been previously diagnosed to be diabetic before presentation while the remaining $18(90 \%)$ had not been previously diagnosed by any form of screening prior to their presentation and admission in the hospital (Table 3).

\section{Parental Financial Constraints}

Cost of care for all the patients was out of pocket and borne by the respective parents. Concerning financing the care of the admitted children, 7 of the parents experienced financial constraints limiting access to insulin and other

Table I Mode of Presentation of Childhood Diabetes

\begin{tabular}{|l|l|l|l|l|}
\hline Presentation & EKSUTH & LTH & Cumulative Frequency & Cumulative Percent (\%) \\
\hline Diabetic ketoacidosis & 8 & 5 & 13 & 65.0 \\
Polyuria, Polydipsia, Polyphagia, weight loss & 4 & 1 & 5 & 25.0 \\
Abdominal pain, bed wetting & 2 & 0 & 2 & 10.0 \\
Total & 14 & 6 & 20 & 100.0 \\
\hline
\end{tabular}


Table 2 Types of Childhood Diabetes Seen at EKSUTH and LTH

\begin{tabular}{|l|l|l|l|l|}
\hline Type of Diabetes & EKSUTH & LTH & Cumulative Frequency & Cumulative Percent (\%) \\
\hline Type I diabetes & 13 & 5 & 18 & 90.0 \\
Type 2 diabetes & 1 & 0 & 1 & 5.0 \\
Glucocorticoid-induced diabetes & 0 & 1 & 1 & 5.0 \\
Total & 14 & 6 & 20 & 100.00 \\
\hline
\end{tabular}

drugs needed in the care of the children. Four $(80.0 \%)$ of the 5 mortalities reported in the study experienced such financial constraints. The child discharged against medical advice also experienced financial constraints. While, 1 (7.1\%) of the 14 children discharged well and alive, experienced financial constraints.

\section{Outcome of Children and Association with Gender, Disease Presentation and Financial Constraints}

Fourteen $(70.0 \%)$ had a very good outcome and were discharged well and alive and are being followed up at the endocrinology clinic, however five $(25.0 \%)$ died from complications of diabetes mellitus. The deaths occurred at home following complications of diabetes due to prolonged non-availability of insulin because of poverty when free donated stocks were exhausted (circumstances surrounding their death was ascertained through verbal autopsy). One of the children had to leave against medical advice (Table 3 ) as the parents could not afford the cost of care during admission and the parents believed more in traditional remedy.

Mortality was more amongst those presenting with DKA, the male gender and the age group above 10 years but no statistical significance. On the other hand the

Table 3 Characteristics of Childhood Diabetics at EKSUTH and LTH

\begin{tabular}{|c|c|c|c|c|c|}
\hline Sex & $\begin{array}{l}\text { Age (Years) at } \\
\text { Presentation }\end{array}$ & Presenting Clinical Feature & $\begin{array}{l}\text { DM Diagnosed Before } \\
\text { Presentation (No = I, } \\
\text { Yes = 2) }\end{array}$ & Type of DM & Outcome \\
\hline \multicolumn{6}{|l|}{ EKSUTH } \\
\hline $\mathrm{F}$ & 5 & DKA & I & I & LAMA \\
\hline $\mathrm{F}$ & 9 & DKA & I & I & Alive \\
\hline $\mathrm{F}$ & 11 & DKA & I & I & Dead \\
\hline M & 11 & DKA & 1 & 1 & Alive \\
\hline M & 15 & DKA & 1 & I & Dead \\
\hline $\mathrm{F}$ & 15 & DKA & I & I & Alive \\
\hline $\mathrm{F}$ & 16 & DKA & I & I & Alive \\
\hline M & 16 & DKA with left hemispheric CVD & 1 & I & Dead \\
\hline $\mathrm{F}$ & 12 & Weight loss, Polyuria & 1 & 2 & Alive \\
\hline M & 14 & Weight loss, Polyuria & 1 & I & Alive \\
\hline $\mathrm{F}$ & 15 & Weight loss, Polyuria & 2 & 1 & Alive \\
\hline $\mathrm{F}$ & 12 & Polyuria & I & I & Alive \\
\hline $\mathrm{F}$ & 13 & Acute abdomen & I & I & Alive \\
\hline $\mathrm{F}$ & 16 & Short stature, bed wetting, weight loss & 1 & 1 & Dead \\
\hline \multicolumn{6}{|l|}{ LTH } \\
\hline M & 9 & DKA & 1 & I & Alive \\
\hline M & 10 & DKA & 1 & I & Dead \\
\hline $\mathrm{F}$ & 13 & DKA & 1 & 1 & Alive \\
\hline $\mathrm{F}$ & 13 & DKA & 2 & 1 & Alive \\
\hline $\mathrm{F}$ & 15 & $\begin{array}{l}\text { DKA in a nephrotic patient on } \\
\text { steroid therapy }\end{array}$ & 1 & $\begin{array}{l}\text { Glucocorticoid- } \\
\text { induced DM }\end{array}$ & Alive \\
\hline M & 14 & Weight loss, Polyuria & I & 1 & Alive \\
\hline
\end{tabular}

Abbreviations: EKSUTH, Ekiti State University Teaching Hospital; LTH, LAUTECH Teaching Hospital; DKA, diabetic ketoacidosis; DM, diabetes mellitus; LAMA, left against medical advice; $M$, male; $F$, female. 
association between the greater proportions of deaths recorded in children with financial constraints was statistically significant $(p=0.03)$. These associations are shown in Table 4

\section{Discussion}

The study shows that diabetes mellitus is not an uncommon paediatric endocrine disorder in the paediatric endocrinology clinics of EKSUTH and LTH, Nigeria. The mean age of 12.1 years of the patients at presentation is consistent with the findings of previous studies from Nigeria. ${ }^{6,8-10}$ However, reports from Saudi Arabia show a markedly lower mean age of 6.7 years. This is possibly due to racial differences. Most of the patients were aged above 10 years at presentation supporting the fact that there is increasing incidence of diabetes mellitus with age among children. ${ }^{8}$

The present study shows female preponderance similar to other studies from Nigeria and Africa. $6,8,9,13$ The exact reason for this is unknown but there are postulations that it may be due to hormonal changes accompanying puberty particularly the increase in growth hormone and oestrogen which is greater in females. ${ }^{6}$ Also there is increased cytokines which can lead to insulin resistance. ${ }^{14}$ Moreover, it has been documented that $78 \%$ of those affected by autoimmune diseases are women ${ }^{15}$ and type $1 \mathrm{DM}$ is an autoimmune disease.

Diabetic ketoacidosis was an initial presentation in $65.0 \%$ of the patients managed for diabetes. Even though this value is not as high as the values reported by many authors in Nigeria and Africa, ${ }^{8,9,16,17}$ it is still higher than

Table 4 Association Between Outcome, Diabetes Presentation, Age, Sex and Financial Constraints

\begin{tabular}{|l|l|l|l|l|}
\hline & Alive $\mathbf{n}$ (15) & Dead $\mathbf{n}$ (5) & $\mathbf{X}^{2}$ & p value \\
\hline $\begin{array}{l}\text { Age } \\
\begin{array}{l}5-10 \text { years } \\
>10 \text { years }\end{array}\end{array}$ & 3 & 1 & & \\
\hline $\begin{array}{l}\text { Sex } \\
\text { Male } \\
\text { Female }\end{array}$ & 4 & 4 & 0.00 & 0.72 \\
\hline $\begin{array}{l}\text { Presentation } \\
\text { DKA } \\
\text { Non DKA states }\end{array}$ & 6 & 3 & & \\
\hline $\begin{array}{l}\text { Financial constraints } \\
\text { Yes } \\
\text { No }\end{array}$ & 3 & 2 & 1.83 & 0.21 \\
\hline
\end{tabular}

what is found in developed countries such as the USA $(25.5 \%)^{18}$ and Sweden $(15.2 \%)^{19}$ and suggests that most patients with diabetes in this environment will present with DKA at the point of diagnosis. It is worthy of note that $83.3 \%$ of the patients at LTH centre presented with DKA which is similar to other single centre experiences in Nigeria and Africa. ${ }^{8,9,16,17}$ The high rates of children presenting with DKA demands more attention from the point of view of identifying interventions that will reverse or prevent this trend, which can easily be achieved by early detection and appropriate management of diabetes. This is the case in developed countries where there is a lower prevalence of DKA because of the higher level of diabetes awareness and better health seeking behaviour in such climes. ${ }^{13}$ It is, however, possible that the prevalence of DKA at first diagnosis in this report is not as high as other previous reports in Nigeria because of the increased screening and awareness of diabetes in children ${ }^{20}$ and the impact of the training programs by the PETCWA in collaboration with ISPAD and ESPE.

The majority $(90.0 \%)$ of patients in this study had type 1 diabetes mellitus as expected concerning diabetes in children. ${ }^{21}$ Clinicians should be on the lookout for other types of diabetes, especially type $2 \mathrm{DM}$ and different forms of presentation of childhood diabetes for early diagnosis and proper management. ${ }^{22}$ One of the patients who presented with acute abdomen was actually scheduled for surgery but when found to have very high random blood glucose preoperatively, the possibility of DM was entertained and she was later confirmed to have type $1 \mathrm{DM}$. Surgery was cancelled and she is currently doing well on insulin. It is very probable that there may be many unpublished reports of missed diabetic children wrongly managed for meningitis, pneumonia, cerebral malaria and acute abdomen who in retrospect might have had diabetic ketoacidosis but died because of wrong diagnosis and management. There is a need to encourage more educational programmes on the symptoms of childhood diabetes mellitus and DKA in all schools to enhance early presentation, diagnosis and management of childhood diabetes so as to reduce the burden of diabetic complications and mortality.

The case fatality rate among patients managed for diabetes in these hospitals was $25.0 \%$. This is remarkably higher than the findings of other studies that reported $4.8 \%$ and $12.5 \%{ }^{8,23}$ However, there is a higher value of $42.6 \%$ that was reported by Majaliwa et al in Sudan. ${ }^{17}$ A common factor among the diabetic patients who died in this report was poverty which led to their inability to procure and 
sustain insulin therapy. Lack of access to insulin is the most common cause of death in diabetic patients worldwide. $^{1,4}$ Our personal observation was that when free insulin and glucometer strips provided by IDF/Life for a Child in collaboration with SPAEN were available, the patients had good blood glucose control but as soon as the free stock got exhausted they began to have problems controlling their blood glucose. This is a common experience in most paediatric endocrinology clinics in developing countries. ${ }^{24,25}$ There is a need for more advocacies for government to provide free insulin for diabetic children in developing countries. There is also a need for physicians managing impoverished diabetic children to closely follow them up and source alternative help for their sustenance when free stocks of insulin are exhausted in order to mitigate the high mortality of diabetic children: no diabetic child should die!

Among our patients, there are a few exceptional type 1 DM patients whose parents are highly motivated and regular on insulin. These patients also displayed good intelligence and are able to regulate their insulin in relation to their blood glucose level. They are growing very well and recorded minimal dysglycaemia. Patients' intelligence, parents' motivation/cooperation and quality of diabetic education are other factors that will greatly contribute to the survival of children living with diabetes.

Only one of the patients left against medical advice while the rest are on follow up in the endocrinology clinic. This suggests a good understanding of the nature of the disease and willingness to cooperate with follow up. Some other authors have reported high discharge against medical advice and clinic default rates because of low education and high financial implications..$^{9,10}$

\section{Conclusion}

Type 1 diabetes mellitus remains the most predominant form of diabetes in children and the most common mode of presentation is DKA. The proportion of the mortality of diabetic children at home is unacceptably high. Strategies that will identify childhood diabetes before development of DKA need to be identified as one expects a window period of months to years, between development of diabetes and DKA. Donor agencies and the government need to step up their efforts to make insulin freely available to diabetic children and assist in making the care of diabetic children on admission free in order to mitigate the effect of poverty on their survival.

\section{Compliance with Ethical Standards}

- Disclosure of potential conflicts of interest; The authors declare that there is no conflict of interest in the conduct and write up of this manuscript. The study is not sponsored by any funding agency.

- Research involving Human Participants: There was no collection of blood samples and nothing was done that may negatively affect the patients during and after the conduct of the index study. Data about patients was kept confidential.

- Informed parental consent: The informed consent we obtained was informed parental consent and information about the patient was recorded and kept with their parent's consent.

- Ethical approval for the study was granted by the Ethics and Research Committee of the Ekiti State Teaching Hospital, Ado Ekiti, Ekiti State, and LAUTECH Teaching Hospital, Osogbo, Osun State, Nigeria. (Ethics Approval Numbers: EKSUTH/A67/2020/07/005 and LTH/EC/2020/ 08/469).

\section{Disclosure}

The authors report no conflicts of interest for this work.

\section{References}

1. International Diabetes Federation. Incidence of diabetes. Diabetes Atlas. 2019.

2. International Diabetes Federation. Incidence of diabetes. Diabetes Atlas. 2017

3. Umar UL. Pattern of presentation of type 1 diabetic patients in Kano, Nigeria. Niger J Basic Clin Sci. 2016;13:85-88.

4. Gale EA. Dying of diabetes. Lancet. 2006;368(9548):1626-1628.

5. International Diabetes Federation. Global IDF/ISPAD Guideline for Diabetes in Childhood and Adolescence; 2011.

6. Onyiriuka AN, Ifebi E. Ketoacidosis at diagnosis of Type 1 diabetes in children and adolescents: frequency and clinical characteristics. $J$ Diabetes Metab Dis. 2013;12:47.

7. Oyenusi EE, Nwaogu NTL, Oduwole AO. Ketoacidosis at diagnosis of Type 1 diabetes in children and adolescents in Lagos, South-West Nigeria: the pattern over 10 years. African J Diabetes Med. 2016;24:2.

8. Jaja T, Yarhere I. The pattern of presentation and trends of childhood diabetes mellitus in Port Harcourt, Southern Nigeria. Brit Med Med Res. 2015;5:247-253.

9. Ibekwe UM, Ibekwe CR. Pattern of Type 1 diabetes mellitus in Abakaliki, South-eastern Nigeria. PediatricOncall J. 2011;8:59-62.

10. Ugege O, Ibitoye PK, Jiya NM. Childhood diabetes mellitus in sokoto, north-western Nigeria: A ten year review. Sahel Med J. 2013;16(3):97-101. doi:10.4103/1118-8561.121910

11. Bialo SR. Rare complications of pediatric diabetic ketoacidosis. World J Diabetes. 2015;6(1):167-174. doi:10.4239/wjd.v6.i1.167

12. World Health Organization. Global Report on Diabetes. Geneva; 2016.

13. Reddy Y, Ganie Y, Pillay K. Characteristics of children presenting with newly diagnosed type 1 diabetes. S Afr J CH. 2013;7 (2):46-48. 
14. Mooney RA, Senn J, Cameron S, et al. Suppressors of cytokine signaling1 and -6 associate with and inhibit the insulin receptor: a potential mechanism for cytokine-mediated insulin resistance. $J$ BiolChem. 2001;276(28):25889-25893.

15. Gleicher N, Barad DH. Gender as risk factor for autoimmune diseases. Journal of Autoimmunity. 2007;28(1):1-6. doi:10.1016/j.jaut.2006.12.004

16. Majaliwa ES, Elusiyan BE, Adesiyun OO, et al. Type 1 diabetes mellitus in the African Population: epidemiology and management challenges. Acta Biomed. 2008;79:255-259.

17. Elusiyan JB, Kareem AJ, Olorunmoteni OE, Odunlade OC. Pattern and outcome of diabetic ketoacidosis among children with type 1 diabetes mellitus at Ile-Ife, Nigeria. Ann Health Res. 2019;5(2):174 182. doi:10.30442/ahr.0502-19-49

18. Rewers A, Klingensmith G, Davis C, et al. Presence of Diabetic Ketoacidosis at Diagnosis of Diabetes Mellitus in Youth: the Search for Diabetes in Youth Study. Pediatrics. 2008;121(5):1258-1266. doi:10.1542/peds.2007-1105

19. Hekkala A, Knip M, Veijola R. Ketoacidosis at Diagnosis of Type 1 Diabetes in Children in Northern Finland: temporal changes over 20 years. Diabetes Care. 2007;30(4):861-866. doi:10.2337/dc06-2281
20. Oluwayemi IO, Brink SJ, Oyenusi EE, Oduwole OA, Oluwayemi MA. Fasting Blood Glucose Profile among Secondary School Adolescents in Ado-Ekiti, Nigeria. J Nutr Metab. 2015;4.

21. Cooke DW, Plotnick L. Type 1 Diabetes Mellitus in Pediatrics. Pediatrics in Rev. 2008;29(11):374-385. doi:10.1542/pir.29-11-374

22. Oluwayemi IO, Airemionkhale A.Type 2 Diabetes in a Nigerian Adolescent:Diagnostic and Management Challenges in a Resource poor Setting. Int J Pediatrics Neonatal Health. 2017;1(3):74-76. doi:10.25141/2572-4355-2017-3.0074

23. John C, Abok II, Yilgwan C. Clinical Profile of Childhood type 1 diabetes mellitus in Jos, Nigeria. Afr J Diab Med. 2013;21(1):11-13.

24. Elusiyan JBE, Okeniyi JAO, Adegoke OO. Challenges of managing childhood diabetes mellitus in Nigeria. Niger Endocrin Pract. 2008;2:111-115.

25. Elusiyan JBE, Anyabolu HC, Odunlade OC, Oke OJ. Challenge of managing endocrine disorders in a resource constraint setting: A report based on two cases. Niger J Health Sci. 2015;14:72-75.

Diabetes, Metabolic Syndrome and Obesity: Targets and Therapy

Dovepress

\section{Publish your work in this journal}

Diabetes, Metabolic Syndrome and Obesity: Targets and Therapy is an international, peer-reviewed open-access journal committed to the rapid publication of the latest laboratory and clinical findings in the fields of diabetes, metabolic syndrome and obesity research. Original research, review, case reports, hypothesis formation, expert opinion and commentaries are all considered for publication. The manuscript management system is completely online and includes a very quick and fair peer-review system, which is all easy to use. Visit http://www.dovepress.com/testimonials.php to read real quotes from published authors.

Submit your manuscript here: https://www.dovepress.com/diabetes-metabolic-syndrome-and-obesity-targets-and-therapy-journal 